\title{
When to stay, when to disperse and where to go: survival and dispersal patterns in a spatially structured seabird population
}

\author{
Albert Fernández-Chacón, Meritxell Genovart, Roger Pradel, Giacomo Tavecchia, Albert Bertolero, \\ Julia Piccardo, Manuela G. Forero, Isabel Afán, Jordi Muntaner and Daniel Oro
}

A. Fernández-Chacón, (afernandez@imedea.uib-csic.es), M. Genovart, G. Tavecchia and D. Oro, Population Ecology Group, Inst. Mediterrani d'Estudis Avançats (IMEDEA, CSIC-UIB), Miquel Marqués 21, ES-07190 Esporles, Spain. - R. Pradel, Biostatistics and Population Biology Group, Centre d'Ecologie Fonctionelle et Evolutive, UMR 5175, Campus CNRS, 1919 Route de Mende, FR-34293 Montpellier, France. - A. Bertolero, Aquatic Ecosystems, Inst. de Recerca i Tecnologia Agroalimentàries (IRTA), Carretera Poble Nou km 5.5, ES-43540 Sant Carles de la Ràpita, Spain. - J. Piccardo, Associació Ornitologica Picampall, Trinquet 10-12, ES-43580 Deltebre, Spain. - M. G. Forero, Dept of Conservation Biology, Estación Biológica de Doñana (CSIC), Avenida Américo Vespucio s/n, ES-41092 Sevilla, Spain. - I. Afán, Remote Sensing and GIS Laboratory, Estación Biológica de Doñana (CSIC), Avenida Américo Vespucio s/n, ES-41092 Sevilla, Spain. - J. Muntaner, Servei d'Agents de Medi Ambient, Conselleria d'Agricultura, Medi Ambient i Territori del Govern de les Illes Balears, Gremi Corredors 10, ES-07009 Palma, Spain.

\begin{abstract}
Dispersal is a key process for the population dynamics of spatially structured populations (at local and metapopulation levels), so the understanding of the mechanisms underlying the movement of individuals in space and time is important for evolutionary and ecological studies. Here we analyzed, for the first time, a long-term (1992-2009) multi-site capturerecapture database collected at four local populations of a long-lived seabird, the Audouin's gull Larus audouinii, covering $90 \%$ of its total world population. Those local populations show different ecological and demographic features that allow us to assess the influence of several key factors involved in breeding dispersal patterns at large spatio-temporal scales. A recently developed analytical tool in mark-recapture modelling, the multi-event approach, allowed us to obtain separate departure and settlement probabilities and test different biological hypotheses for each step of the dispersal process. Our results revealed that site fidelity was the most common strategy among breeders, and dispersal was only high from the site with the lowest population size and habitat quality. However, departures from the two largest local populations increased over the study period in response to severe ecological perturbations. Dispersers chose different settlement patches depending on their site of origin, with settlement choices determined by the population size of the destination colony rather than by the local reproductive performance, foraging area (a proxy of food availability) or distance to the destination site. Our results indicate that a breeding site is not abandoned by breeders unless a series of cumulative perturbations occur; once dispersing, settlement is directed towards densely populated sites, with dispersers using population size to rapidly assess the quality of the breeding patch.
\end{abstract}

Dispersal is the movement of individuals between patches in space and time and guarantees connectivity of spatially structured populations (Hanski 1999, Clobert et al. 2001). Dispersal, together with birth and mortality, plays a major role in the dynamics of populations at local and metapopulation levels: for instance, dispersal events are responsible for the formation of populations (i.e. colonization) and are also important for their growth (Brown and KodricBrown 1977, Gotelli 1991, Oro and Ruxton 2001, Kildaw and Irons 2005). Nevertheless, compared to the factors influencing reproduction and mortality, dispersal and its determinants still remain poorly understood (Greenwood and Harvey 1982, Hanski 1999, Clobert et al. 2001, Liu and Zhang 2008) but this knowledge has much improved in recent years thanks to the advances in the large-scale monitoring of multiple populations and the development of new analytical tools (Nathan 2001).
Dispersal can be seen as a sequential two-step process in which individuals have first to decide whether or not to remain in the current site (fidelity decisions) and secondly, where to go once they have left their previous site (settlement decisions) (Forero et al. 1999, Clobert et al. 2001). The partition of dispersal into fidelity and settlement decisions permits investigation of the key factors involved in each step of the dispersal process (Grosbois and Tavecchia 2003). Fidelity may be preferred because it promotes kinship (Friesen et al. 1996) and it improves foraging efficiency and predator defence thanks to a better knowledge of the environment (Greenwood and Harvey 1982), but it can be negatively affected by factors such as individual or colonial breeding failure by predation or food depletion, mate loss and risk of inbreeding (Danchin et al. 1998, Forero et al. 1999, Serrano et al. 2001, Parejo et al. 2006). On the other hand settlement decisions may 
be influenced by the presence, larger density or higher breeding success of conspecifics or heterospecifics in a patch (Smith and Peacock 1990, Mönkkönen et al. 1997, Danchin et al. 1998, Cam et al. 2004, Parejo et al. 2006, Péron et al. 2010) and negatively affected by spatial factors such as distance between patches (Forero et al. 1999, Oro and Pradel 1999, Serrano et al. 2001).

Here we examined the fidelity and settlement components in the dispersal of the Audouin's gull Larus audouinii, a long-lived colonial seabird showing high fidelity but also high dispersal capabilities when the quality of environment deteriorates (Oro and Muntaner 2000, Oro et al. 2011). An evolutionary history linked to unstable and ephemeral breeding environments has selected for the strong mobility and nomadic behaviour recorded in the species (Martinez-Abrain et al. 2003, Parejo et al. 2006), with both philopatric and dispersing individuals showing similar demographic rates and hence relatively low dispersal costs (Oro et al. 2011). Owing that populations of Audouin's gulls are known to be connected through dispersal of individuals (Oro and Pradel 1999, Tavecchia et al. 2007), we assess here the ecological factors influencing dispersal decisions. We focused on the breeding dispersal (i.e. the dispersal of established breeders) among four local populations monitored simultaneously from 1992 to 2009 , covering the $90 \%$ of the world population and thus increasing the spatio-temporal scale of previous studies (Cam et al. 2004). Each of these sites showed particular ecological and demographic features influenced by local environmental stochasticity (see below), providing a useful model to study the determinants of fidelity and settlement in breeding dispersal. Capture-recapture data collected during the study period at each site were analysed using a recently developed analytical tool in mark-recapture modelling, the multi-event approach (Pradel 2005), which permits to split the dispersal process in fidelity and settlement probabilities (Grosbois and Tavecchia 2003) and yields a more robust estimation of the parameters of interest by including extra parameters for latent (i.e. not observable) processes.

\section{Biological hypotheses}

The first step in the decision-making dispersal process concerns fidelity to the breeding site. Assuming that decisions regarding where to breed in year $t+1$ are made in year $t$, conditions experienced in the current breeding patch may influence site fidelity as a first order-Markovian process. Under this assumption, deterioration in habitat quality should trigger dispersal as a response to a poor breeding output (Danchin et al. 1998, Forero et al. 1999, Oro et al. 1999, Serrano et al. 2001, Schaub and von Hirschheydt 2009). However, it is known that experienced breeders of many seabirds, including gulls, show high site tenacity (Greenwood and Harvey 1982), so a low breeding dispersal probability, regardless of the current habitat conditions, could also be expected (Oro et al. 1999, Cam et al. 2004). Therefore, we first tested a general null hypothesis of invariant fidelity among years or colonies. We then tested for variability in fidelity among colonies and years as a response to colony-specific habitat quality and/or changing environmental conditions. For instance, fidelity should be higher at sites with denser population sizes and large foraging areas, which should translate into a better protection against predators, higher food supply and good breeding performance (Oro et al. 2006). Finally, we tested for a temporal negative trend in fidelity at the sites where habitat quality deteriorated during the study (see below).

The second step in the dispersal process concerns settlement decisions, which require a previous assessment of the quality of the available breeding sites. This pace is time demanding and requires an energy investment (Clobert et al. 2001), and individuals may rely on cues such as the density of conspecifics or heterospecifics (Smith and Peacock 1990, Mönkkönen et al. 1997) and their breeding performance (Boulinier and Danchin 1997). We tested the effects of colony size, surface of foraging area and breeding success as indicators of habitat quality for settlement in Audouin's gulls. In our study system, local population size may be a good indicator of habitat quality because of the generally more suitable habitat of the sites containing the largest colonies (see below). Moreover, high immigration rates have been recorded at sites with high population densities (Cam et al. 2004, Tavecchia et al. 2007) and larger densities have been linked with higher abundance of resources per capita (Ruiz et al. 1998, Oro and Pradel 2000, Tavecchia et al. 2007, Almaraz and Oro 2011). Accordingly, the surface of foraging area or continental shelf around a colony might also be seen as an indicator of habitat quality (via food availability) that may influence settlement decisions. Breeding performance can be also a useful cue for habitat selection if it is temporally autocorrelated, but this information needs to be gathered before settlement by prospecting the different habitat patches during the previous breeding season (Danchin et al. 1998, Clobert et al. 2001) a behaviour documented on prebreeders or failed breeders (Cadiou et al. 1994, Boulinier et al. 1997, Schjørring et al. 1999). Because breeding activity limits the ability of breeders to prospect potential future breeding sites within the same season (Oro and Ruxton 2001, Hénaux et al. 2007), dispersing individuals may be forced to settle in patches close to their former breeding site due to 'information barriers', sensu Forbes and Kaiser (1994) (see also Oro and Pradel 1999). Previous studies in Audouin's gull show that breeding adults may forage at distances up to ca $200 \mathrm{~km}$ (Arcos and Oro 1996, J. M. Arcos pers. comm.), so prospecting other sites while breeding should be rather limited in our study system (Fig. 1). In addition, breeding success seems not to be temporally auto-correlated in this species (Oro and Ruxton 2001, Cam et al. 2004), so cueing on reproductive performance may be unreliable. Based on our previous knowledge of the species' population dynamics in the study system, we expected colony size (i.e. the number of breeding pairs) to perform better than the other variables as indicator of local habitat quality and show a positive association with settlement. We also predicted a positive association between settlement and foraging area around each breeding site, but not between breeding success and settlement probability (see above). Finally, we also tested the hypothesis that settlement probabilities would decrease with distance (Oro and Pradel 1999, Péron et al. 2010). 


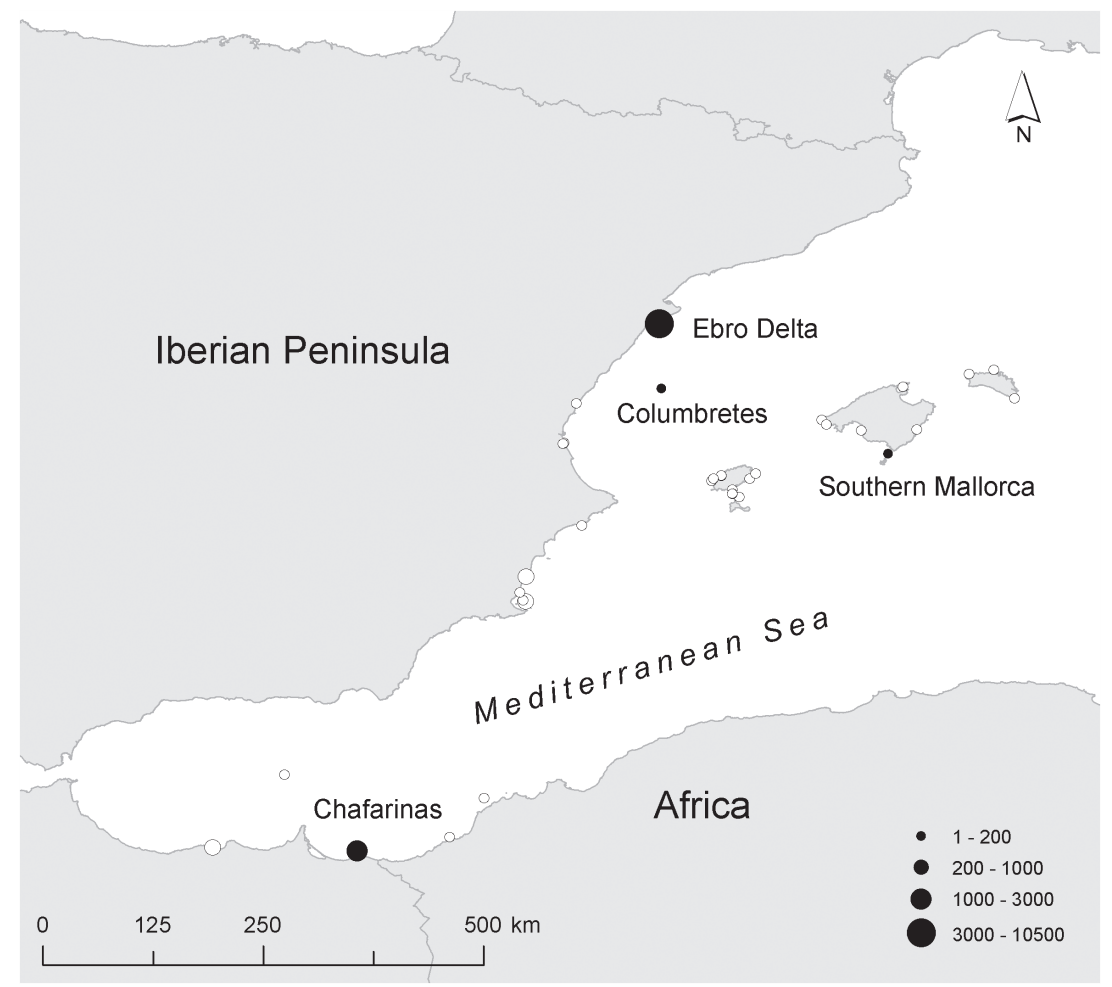

Figure 1. Distribution and size (number of breeding pairs) of the main local populations of Audouin's gull in the western Mediterranean. Black circles indicate the location of the four study sites, with their corresponding names, and white circles represent other colonies known to exist (or have existed at some point in time) out of our study area.

In summary, the aims of the present study are not only to estimate breeding dispersal in Audouin's gulls with reliability, but especially to identify the mechanisms driving breeding dispersal at large spatio-temporal scales by testing meaningful biological hypotheses on fidelity and settlement probabilities in a system with a high heterogeneity in habitat quality.

\section{Material and methods}

\section{Study populations}

We studied four local Audouin's gull populations in the western Mediterranean (Fig. 1): Punta de la Banya at the Ebro Delta $\left(40^{\circ} 33^{\prime} \mathrm{N}, 0^{\circ} 39^{\prime} \mathrm{E}, 2500\right.$ ha), Columbretes islands $\left(39^{\circ} 54^{\prime} \mathrm{N}, 0^{\circ} 41^{\prime} \mathrm{E}, 19 \mathrm{ha}\right)$, Chafarinas islands, $\left(35^{\circ} 11^{\prime} \mathrm{N}, 2^{\circ} 26^{\prime} \mathrm{W}, 50 \mathrm{ha}\right)$ and southern Mallorca islets, in the Balearic islands $\left(39^{\circ} 11^{\prime} \mathrm{N}, 2^{\circ} 58^{\prime} \mathrm{E}, 347 \mathrm{ha}\right)$. This assemblage holds ca the $90 \%$ of the world's total population of the species, with the remaining $10 \%$ found in other localities of the western Mediterranean (Balearic archipelago, North African coast, south eastern Iberia) as well as in the eastern and central parts of the basin. The Chafarinas islands, off the Moroccan coast, harbour the most distantly located population in our study area (more than $600 \mathrm{~km}$ from the Ebro Delta), whereas the Ebro Delta and Columbretes islands hold the two closest populations, separated by $80 \mathrm{~km}$ of sea and partially sharing feeding grounds in the Eastern Iberian continental shelf. Heterogeneity is high in the study system and colonies show very different number of breeding pairs, average breeding success and size of foraging areas (Table 1). All study sites except that in the Ebro Delta are located in offshore small rocky islets and are free of terrestrial predators. Habitat suitability is the highest in the Ebro Delta owing to its larger surface of breeding habitat and larger foraging areas with relative high marine productivity. Here, gulls colonized the site in 1981 and population growth rate followed a logistic shape with extremely high growth rates in the first years (Tavecchia et al. 2007, Almaraz and Oro 2011). However, since 1999, a small number of red foxes Vulpes vulpes are regularly present in this colony and prey on gulls, so deteriorating their breeding performance over the last years (Tavecchia et al. 2007). Ecological features at Chafarinas are intermediate between those found at mainland and island populations; free of carnivores, relatively small surface but lying within a productive

Table 1. Population sizes, foraging areas and breeding success values for each study site. Population sizes correspond to the mean number (median in parenthesis) of breeding pairs at each colony during the period 1995-2009. Breeding success shows the mean values (variance in parenthesis) calculated for the same period at each colony. Foraging areas are calculated as the surface of continental shelf (in $\mathrm{km}^{2}$ ) within a $100 \mathrm{~km}$ radius from each local population.

\begin{tabular}{lccc}
\hline Study site & Population size & Foraging area & Breeding success \\
\hline Ebro Delta & $11560(11328)$ & 10371.51 & $0.57(0.10)$ \\
Columbretes & $157(75)$ & 9647.13 & $0.20(0.08)$ \\
Chafarinas & $2360(2124)$ & 3976.74 & $0.35(0.06)$ \\
Mallorca & $291(303)$ & 5106.71 & $0.66(0.30)$ \\
\hline
\end{tabular}


marine area and close to the coast, where secondary prey are available. Here, deterioration of the habitat has also occurred since 2000 caused by several socio-ecological factors: first, an eradication programme aimed at black rats Rattus rattus has resulted in the weed Lavatera mauretanica invading Audouin's gull breeding habitat (own data). Secondly, cessation in the activity of purse-seine fisheries during the spring months, from which gulls easily obtain food (Pedrocchi et al. 2002, González-Solís 2003), may have caused food shortage most of the years; and finally, the recovery of the local population of the predatory and dominant yellow-legged gulls Larus michahellis after culling during the 90's might have increased the number of competitive interactions between this species and Audouin's gulls (González-Solís 2003).

\section{Data collection}

From 1992 to 2009, a total of 27215 chicks were ringed in the study colonies, and more than 19500 resightings of marked individuals were obtained during the breeding season (from April to June). Details about field protocols can be found elsewhere (Cam et al. 2004, Tavecchia et al. 2007). Data on marked and resighted individuals at each colony was used to build up a capture-recapture dataset where the first capture occasion in an individual encounter history corresponded to the time it was ringed as a chick, and the first recapture corresponded to the first reobservation in a breeding site. For this study, we analysed the dispersal of breeders and thus we focused in the sequence of encounters after the first resighting of a marked individual in a breeding colony. We omitted the first capture as chick and only one resight per season was retained. Given that in ground-nesting gulls it is not always possible to confirm their breeding status, we assumed all of them to be breeding when observed. However, to reduce the bias caused by resighted non-breeders, we removed from our data eight cases in which an individual was resighted in more than one colony in the same breeding season and their breeding status could not be assessed and all the observations corresponding to immature birds (individuals younger than $3 \mathrm{yr}$ old). This makes the earliest possible resighting of a marked bird in a monitored colony to be year 1995, which corresponds to the first possible breeding attempt of an individual belonging to the first cohort (i.e. 1992). Hence, from our 18-yr long capture-resighting data collection, we generated a 15-yr dataset with 7399 individual histories of adult breeders for the analysis of breeding dispersal. The number of breeding pairs at each colony was estimated by performing an annual census of nests, and annual breeding success was estimated as the ratio of the number of chicks fledged per breeding pair (see details in Oro and Pradel 2000, Oro and Ruxton 2001). Sizes of foraging areas (as a proxy of food availability) were calculated as the surface of continental shelf within a $100 \mathrm{~km}$ radius from each local population.

\section{Modelling framework}

Our capture-recapture dataset was analyzed using a multi-event modelling approach with program E-SURGE
(Pradel 2005, Choquet and Nogue 2010). Multi-event models (Pradel 2005) relate the true state of the individual (i.e. breeding at a given colony - dead) with the observed event (i.e. seen - not seen) through a series of conditional probabilities (Supplementary material Appendix 1).

We took advantage of the multi-event approach to split the dispersal process in fidelity and settlement probabilities and to incorporate unobservable states in our modelling, such as an unknown location (hereafter 'ghost site') to model dispersal out of our system and obtain more reliable estimates of model parameters (Jenouvrier et al. 2008, Sanz-Aguilar et al. 2011). Models included the following eight states: four breeding states (one for each breeding site), the state 'alive elsewhere' (i.e. the ghost site), a dead state and two additional recapture states (see below). Note that the last three states are also unobservable. Transition probabilities between states were modelled in a three step approach to estimate three underlying parameters: survival, departure (the complement of sitefidelity, conditional on survival) and settlement probabilities (conditional on survival and departure).

We first performed a goodness-of-fit (GOF) test to check if our data followed the assumptions of a departure model, in our case, the Arnason-Schwarz (AS) model which assumes all parameters being time-dependent (Brownie et al. 1993, Pradel et al. 2003). GOF tests were developed using program U-CARE (Choquet et al. 2009), which allowed us to detect the source of heterogeneity (i.e. transience or trap dependence) and incorporate this information into our departure model by increasing its complexity (i.e. number of underlying states). Because we detected significant trap dependence at the Ebro Delta and Chafarinas sites (Results), this effect had to be included in our departure model. Following Pradel and Sanz-Aguilar (2012), we introduced two additional recapture states (trap-aware and trapunaware states) in our modelling by means of a fourth step included after settlement, which allowed us to estimate transitions between the two recapture states for the individuals settling at the Ebro Delta and Chafarinas colonies (Supplementary material Appendix 1). At these sites, recapture probabilities refer to the transitions between trapunaware and trap-aware states, whereas for the remaining colonies, recapture and event probabilities are synonyms (Pradel and Sanz-Aguilar 2012). In order to correct for remaining sources of lack of fit, a variance inflation factor $(\hat{c})$, was used to scale model deviances (Lebreton et al. 1992, Tavecchia et al. 2001). Model selection was based on the Akaike's information criterion, corrected for overdispersion (QAIC). We selected our best model as the one with the lowest QAIC value, whereas models that differed in less than 2 points of QAIC $(\triangle \mathrm{QAIC}<2)$ were arbitrarily considered as statistically equivalent.

Model construction followed a step-wise approach to find the most parsimonious structure for the testing of our biological hypotheses. We assessed colony (noted by ' $c$ '), and time (' $\mathrm{t}$ ') effects in survival (' $S$ '), departure $(d)$, settlement $(\Psi)$ and recapture probabilities $(p)$ by combining constancy ('.') or interaction ('*') between these effects. To avoid larger model sets including all the various combinations of potential effects, additive effects of colony with time were not included in the analyses as synchrony among 
breeding colonies was very unlikely. No age effects were considered, as we focused only on one (adult) age class; however, a permanent effect of time since-marking or relative age of the individual (denoted 'a') was left in survival, distinguishing two classes of individuals (newly-seen vs resident or previously seen individuals), a common procedure to control for transient effects (Pradel et al. 1997). We assessed the importance of the identity of the colony of origin on departure probability and the identity of both the departure and destination sites on settlement probabilities. Subsequently, we assessed changes in dispersal probability associated with changing environmental conditions at Chafarinas and the Ebro Delta during the second part of the study by testing two kinds of trends in departure probabilities $(d)$ : a 'fox' trend in Ebro Delta (starting in 1999) and an 'habitat change' trend in Chafarinas (starting in 2000). We also tested the hypothesis of two periods of distinct $d$ (before and after fox arrival in Ebro Delta and before and after the first socio-ecological changes in Chafarinas). Since we only obtained four estimates of site fidelity, we could not test the effects of covariates on that parameter due to a lack of power. Instead, we addressed the effect of external covariates on settlement due to the larger number of settlement transitions resulting from the various combination of movements from and to the different breeding colonies.

The effect of covariates on settlement probabilities cannot be built in the multi-event modelling because E-SURGE lacks a generalized logit with linear effect of sitecovariates. Following Péron et al. (2010) we run a posthoc analysis retrieving the settlement estimates from the selected model and took into account their variances and covariances with a generalized least square approach using the function lscov implemented in MATLAB ver. 7.0 (Supplementary material Appendix 2). Following this approach, we assessed the effects and significance of each predictor variable (distance between sites, mean number of breeding pairs, foraging area and mean breeding success at destination) on settlement probability by conducting regression analyses and performing $t$-tests, using the obtained slopes and their standard errors. The selection of the best predictor(s) of settlement followed a backward approach, departing from the full regression containing all covariates, and removing the least significant ones until all remaining covariates in the model were significant. Transitions from a study site to the ghost site or vice versa were not included in the response variable because this ghost site is not an identifiable location and its local features are unknown. All predictor variables used in the post-hoc analysis were previously standardized.

\section{Results}

\section{Gof testing}

The AS model did not fit our data adequately $\left(\chi_{261}^{2}=939.4\right.$, $\mathrm{p}<0.005)$ and we detected significant transience $(3 \mathrm{Sr}$ test), trap-dependence (2MITEC test) and memory effects (WBWA test). A closer inspection revealed that the Ebro Delta and Chafarinas colonies were mostly responsible for this lack of fit; in particular, trap-dependence at the Ebro Delta was large (test 2CT; $\chi_{12}^{2}=225.34, \mathrm{p}<0.005$ ). Following Pradel and Sanz-Aguilar (2012), transience and trap-dependence effects were integrated into our departure model. Incorporating these effects reduced the structural failure of the model $\left(\chi_{199}^{2}=422.9, \mathrm{p}<0.005, \hat{c}=\right.$ $2.125)$ and yielded a lower overdispersion coefficient that was implemented to scale model deviances.

\section{Multi-event modelling}

Model selection began by fitting the departure model (model 7, Table 2). This model considered state (site, hereafter) and time interactions in survival, departure, settlement and recapture probabilities and distinguished survival of newly and previously seen birds. Model parsimony increased (i.e. the AIC value decreased) when time effects were removed from settlement probability (model 7 vs model 6), survival (model 6 vs model 4) and departure probabilities from Columbretes and Mallorca (model 4 vs model 2), keeping full site and time interactions only in recapture probability. At this point, we kept the structure of model 2 to assess our hypothesis concerning departure probabilities from the Ebro Delta and Chafarinas. Model

Table 2. Ranking of multi-event models of multisite capture-recapture data on Audouin's gull (most parsimonious model in bold), showing the model structure for survival $(S)$, departure $(d)$, settlement $(\Psi)$ and recapture probabilities $(p)$, the number of parameters $(n p)$, deviance (DEV) and QAIC values for each one. $\triangle$ QAIC is the difference in QAIC value when comparing the current model with the selected best model. Akaike weight $\left(\omega_{\mathrm{i}}\right)$ is calculated using the relative likelihoods of the models and represents the probability that a model is the best one of the set.

\begin{tabular}{|c|c|c|c|c|c|c|c|c|c|}
\hline Model & S & $d$ & $\Psi$ & $p$ & $\mathrm{np}$ & Deviance & QAIC & $\triangle \mathrm{QAIC}$ & $\omega_{\mathrm{i}}$ \\
\hline 1 & $a \times c$ & c(EFox, XHab) & c & $\mathbf{c} \times \mathbf{t}$ & 155 & 49571.548 & 23637.787 & 0.000 & $\overline{0.999}$ \\
\hline 2 & $\mathrm{a} \times \mathrm{c}$ & $c(E t, X t)$ & c & $c \times t$ & 179 & 49529.566 & 23666.031 & 28.244 & 0.000 \\
\hline 3 & $\mathrm{a} \times \mathrm{c}$ & $\mathrm{c}(\mathrm{E} 2 \mathrm{~T}, \mathrm{X} 2 \mathrm{~T})$ & c & $c \times t$ & 155 & 49659.424 & 23681.141 & 43.354 & 0.000 \\
\hline 4 & $\mathrm{a} \times \mathrm{c}$ & $c \times t$ & c & $c \times t$ & 216 & 49453.317 & 23704.149 & 66.362 & 0.000 \\
\hline 5 & $\mathrm{a} \times \mathrm{c}$ & c & c & $c \times t$ & 153 & 49756.973 & 23721.046 & 83.259 & 0.000 \\
\hline 6 & $\mathrm{a} \times \mathrm{c} \times \mathrm{t}$ & $\mathrm{c} \times \mathrm{t}$ & c & $c \times t$ & 310 & 49275.968 & 23808.691 & 170.904 & 0.000 \\
\hline 7 & $\mathrm{a} \times \mathrm{c} \times \mathrm{t}$ & $c \times t$ & $c \times t$ & $c \times t$ & 426 & 49072.557 & 23944.968 & 307.181 & 0.000 \\
\hline 8 & $\mathrm{a} \times \mathrm{c}$ & C & C & C & 79 & 51284.051 & 24291.671 & 653.884 & 0.000 \\
\hline 9 & $\mathrm{a}$ & 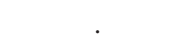 & . & . & 51 & 53244.909 & 25158.428 & 1520.640 & 0.000 \\
\hline
\end{tabular}

Model notation: $\mathrm{E}=$ Ebro Delta. $\mathrm{X}=$ Chafarinas. $2 \mathrm{~T}=$ two periods of constant values; before and after the start of habitat deterioration in 1999 (Ebro Delta) and 2000 (Chafarinas). Fox = linear trend in departure probability since year 1999. Hab = linear trend in departure probability since year 2000 ('habitat change' trend). Age, time, colony effects and constancy on model parameters were denoted as ' $a$ ', ' $t$ ', ' $c$ ' and '.' respectively (Methods). 
Table 3. Survival estimates and their standard errors obtained from model 1 for newly seen $\left(S_{1}\right)$ and resident individuals $\left(S_{2}\right)$. The percentage of transients (individuals never seen again after 1st resighting) was calculated from the ratio $1-\left(\mathrm{S}_{1} / \mathrm{S}_{2}\right)$. Departure probabilities conditional on survival $(d)$ obtained from the model without trend forcing (model 2 ) are also shown, with their standard errors, for each study site.

\begin{tabular}{lcccc}
\hline Study site & $\mathrm{S}_{1}$ & $\mathrm{~S}_{2}$ & Transients $(\%)$ & $d$ \\
\hline Ebro Delta & $0.839 \pm 0.011$ & $0.898 \pm 0.008$ & 6.611 & $0.029 \pm 0.018^{*}$ \\
Columbretes & $0.656 \pm 0.109$ & $0.906 \pm 0.037$ & 27.527 & $0.656 \pm 0.115$ \\
Chafarinas & $0.793 \pm 0.043$ & $0.863 \pm 0.015$ & 8.089 & $0.064 \pm 0.047^{*}$ \\
Mallorca & $0.656 \pm 0.078$ & $0.860 \pm 0.040$ & 23.799 & $0.027 \pm 0.014$ \\
\hline
\end{tabular}

*Average estimates because the retained model included time effects in departure probability at these sites.

selection revealed that models including temporal trends in departures from Chafarinas and the Ebro Delta ('habitat change' and 'fox' respectively) were more parsimonious than those considering two periods of constant departure probabilities at these sites (model 3 vs model 1 ).

\section{Survival, transience and recapture probabilities, and population sizes}

All survival estimates were high, ranging from 0.860 (SE: 0.040 ) to 0.906 (SE: 0.037, Table 3). In contrast to survival, the proportion of transients (individuals never seen again after first recapture) was very different among patches (Table 3 ) and increased with decreasing population size ( $\log$ model, $R^{2}=0.9232, F_{1,2}=37.08, \mathrm{p}<0.01$ ). In the retained model (model 1, Table 2), recapture probabilities were time and site dependent, with the highest mean values corresponding to individuals from the Ebro Delta colony $(0.632 \pm 0.017)$. Compared to the Ebro Delta, Chafarinas showed lower mean recapture rates $(0.339 \pm 0.021)$, but still higher than that of the smaller colonies of southern Mallorca $(0.282 \pm 0.023)$ and
Columbretes $(0.264 \pm 0.027)$. Mean population sizes in the study system ranged from 157 to 11560 breeding pairs (Table 1) and fluctuated across the study period (Fig. 2).

\section{Departure and settlement probabilities}

Departure probabilities were very low at all sites indicating high site fidelity of resident breeders except at Columbretes (0.656, SE: 0.115 , Table 3), the site with the lowest population size. Estimates from the time-varying models showed that, as expected, departure probability increased during the last years of the study at Chafarinas (with up to $35 \%$ of breeders dispersing in 2008) and the Ebro delta (Fig. 3). Settlement estimates from the retained model revealed different behaviours among dispersers depending on where they bred the year before (Table 4). Most birds $(82 \%)$ leaving the Chafarinas islands chose areas out of the study system to settle (ghost site), whereas those leaving southern Mallorca and Columbretes dispersed to the Ebro Delta (100 and 96\%, respectively). Around $87 \%$ of birds leaving the Ebro Delta chose the Columbretes islands as their next breeding location.

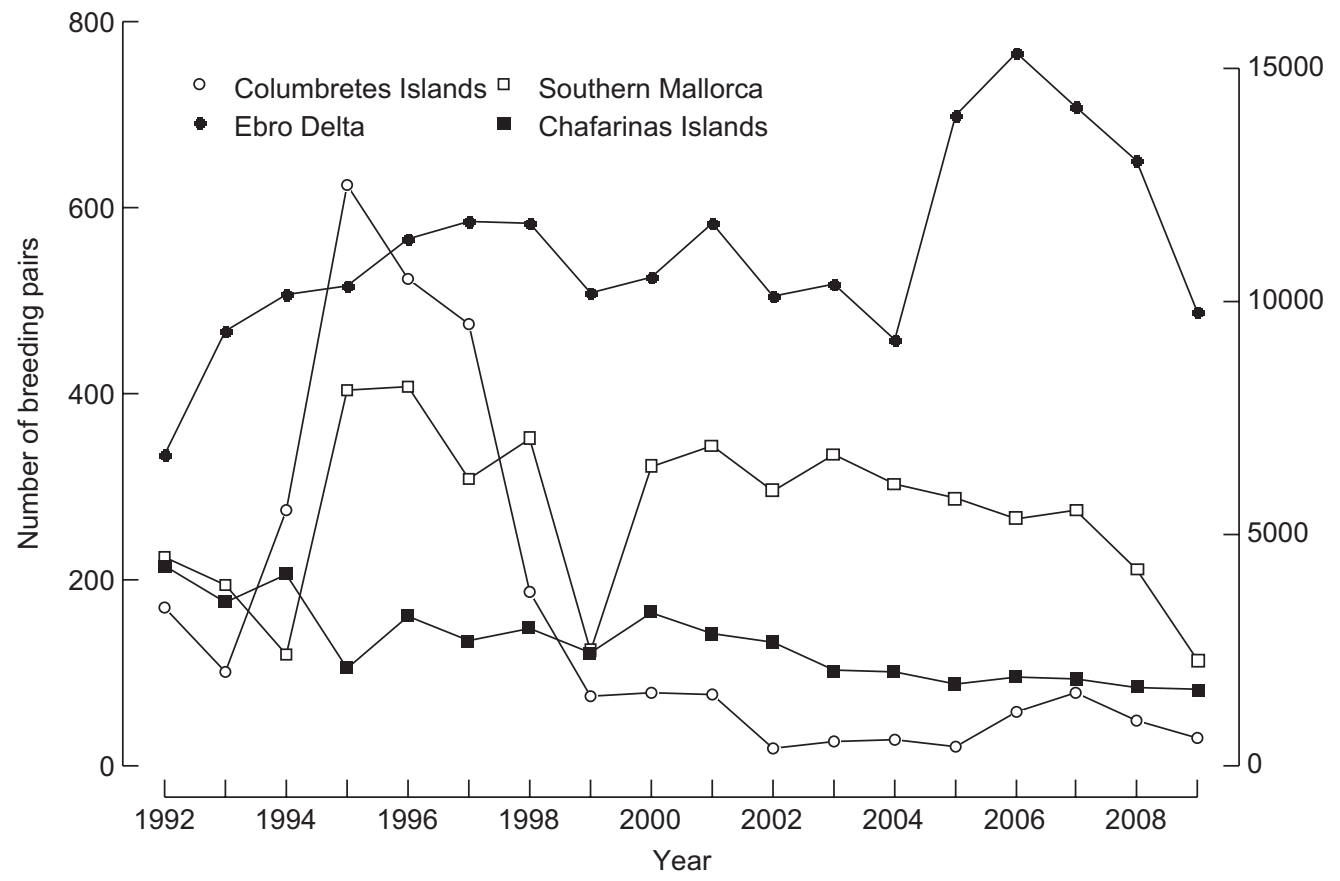

Figure 2. Number of breeding pairs of Audouin's gull at each local population during the study period. The principal y-axis depicts the numbers for Columbretes and southern Mallorca colonies whereas the Ebro Delta and Chafarinas islands numbers are depicted in the secondary y-axis. 


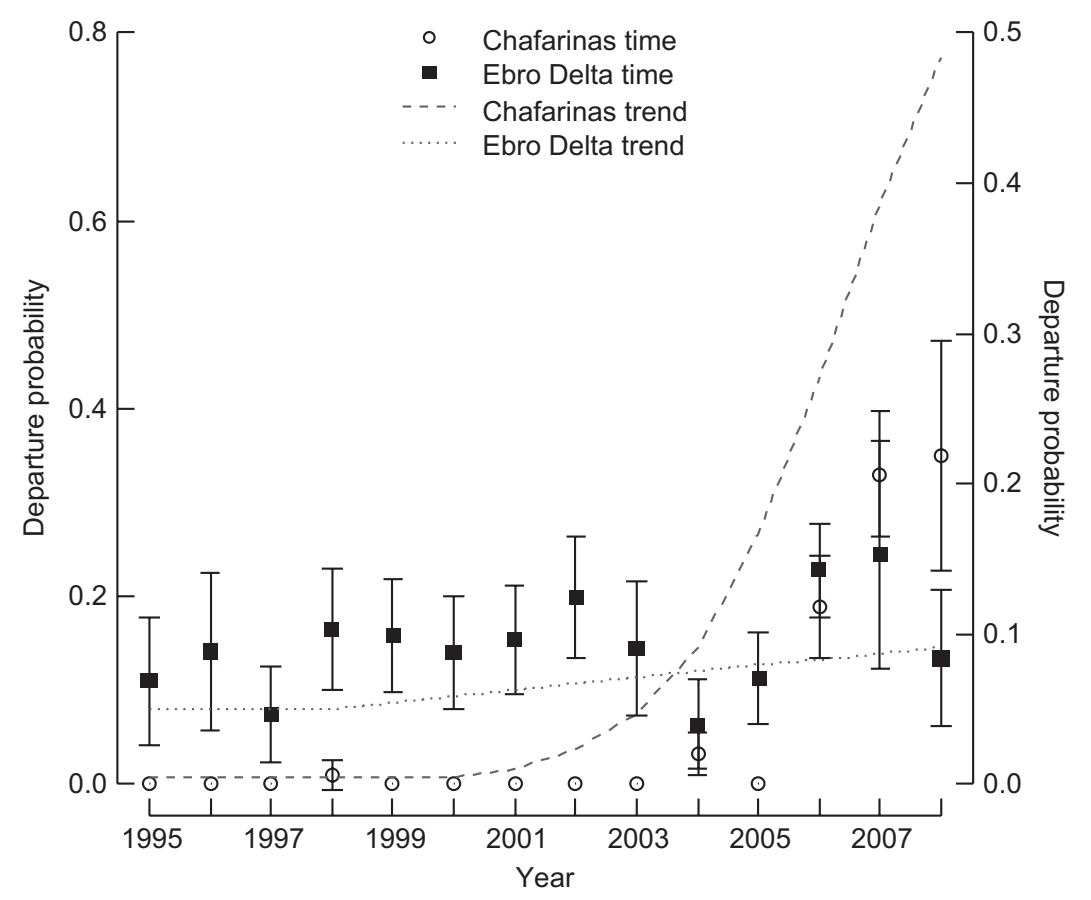

Figure 3. Temporal representation of departure probability estimates for Chafarinas and the Ebro Delta sites obtained from the most parsimonious model and the preferred time dependent model in our set (models 1 and 2, or 'trend' and 'time' models respectively). Model 2 estimates are given as dots with errors bars whereas estimates of model 1 (which are forced by the fox and habitat trends, see methods) are given as dashed and dotted lines, without error bars. The principal $y$-axis depicts departure probabilities at Chafarinas islands whereas the secondary y-axis depicts the corresponding probabilities for the Ebro Delta colony.

We detected a positive and statistically significant relationship between settlement probabilities and size of the destination colony $\left(t_{10}=3.797 ; \mathrm{p}=0.0035\right)$, with settlement probabilities increasing with the number of conspecifics ( $\beta$ slope $=11.613$ (SE: 3.058, Fig. 4). The size of the destination colony was the last remaining predictor of settlement after removing the least significant covariates in a backward approach departing from the full regression model. Foraging area was removed in the first step, followed by breeding success and distance between sites in the second and third steps respectively (Supplementary material Appendix 3). By conducting separate regression analyses, we also assessed the significance of the relationship between each predictor variable and settlement. Distance alone did not explain the observed settlement patterns $\left(t_{10}=-1.549\right.$; $\mathrm{p}=0.152$ ), although this relationship was negative, with reduced probability of settlement the greater the distance to the destination site $(\beta$ slope $=-7.717$; $\mathrm{SE}=4.981$, Fig. 4). Neither foraging area nor breeding success at the destination site influenced settlement decisions $\left(t_{10}=1.759\right.$; $\mathrm{p}=0.109$ and $t_{10}=1.707 ; \mathrm{p}=0.119$ respectively) although the two factors showed a positive relationship with settlement $(\beta$ slope $=8.762 ; \mathrm{SE}=4.632 ; \beta$ slope $=8.5006 ; \mathrm{SE}=$ 3.7942 respectively, Fig. 4).

\section{Discussion}

Our study addresses questions on the factors shaping animal dispersal at large spatio-temporal scales (Paradis et al. 1998, Clobert et al. 2001). We were able to decompose the dispersal process into leaving and settlement decisions, which we have shown can be influenced by different ecological factors. Moreover, the multi-event modelling approach allowed us to account for settlement out of our study area by considering an unobservable state and helped us to solve problems with recapture heterogeneity by including additional recapture states in the model structure. Those methodological improvements resulted in more reliable estimates of survival, recapture, fidelity to the colony and dispersal.

Table 4. Mean settlement probabilities (SE) for Audouin's gulls in our population network, including the ghost site, (Methods). Estimates were obtained from the most parsimonious model (i.e. with the lowest AIC value) in the multi-event modelling.

\begin{tabular}{|c|c|c|c|c|c|}
\hline From/to & Ebro Delta & Columbretes & Chafarinas & S. Mallorca & Ghost site \\
\hline Ebro Delta & & $0.870(0.043)$ & $0.120(0.039)$ & $0.012(0.009)$ & $0.000^{*}$ \\
\hline Columbretes & $0.960(0.029)$ & & $0.000(0.000)$ & $0.035(0.023)$ & $0.007^{*}$ \\
\hline Chafarinas & $0.150(0.032)$ & $0.02(0.029)$ & & $0(0.000)$ & $0.832 *$ \\
\hline Mallorca & $1(0.000)$ & $0(0.000)$ & $0(0.000)$ & & $0.000^{*}$ \\
\hline Ghost site & $0(0.000)$ & $0.026(0.070)$ & $0.970(0.070)$ & $0.000^{*}$ & \\
\hline
\end{tabular}

*Probabilities that were computed as complement to 1 of the other estimates (complementary transitions; see Supplementary material Appendix 1). 

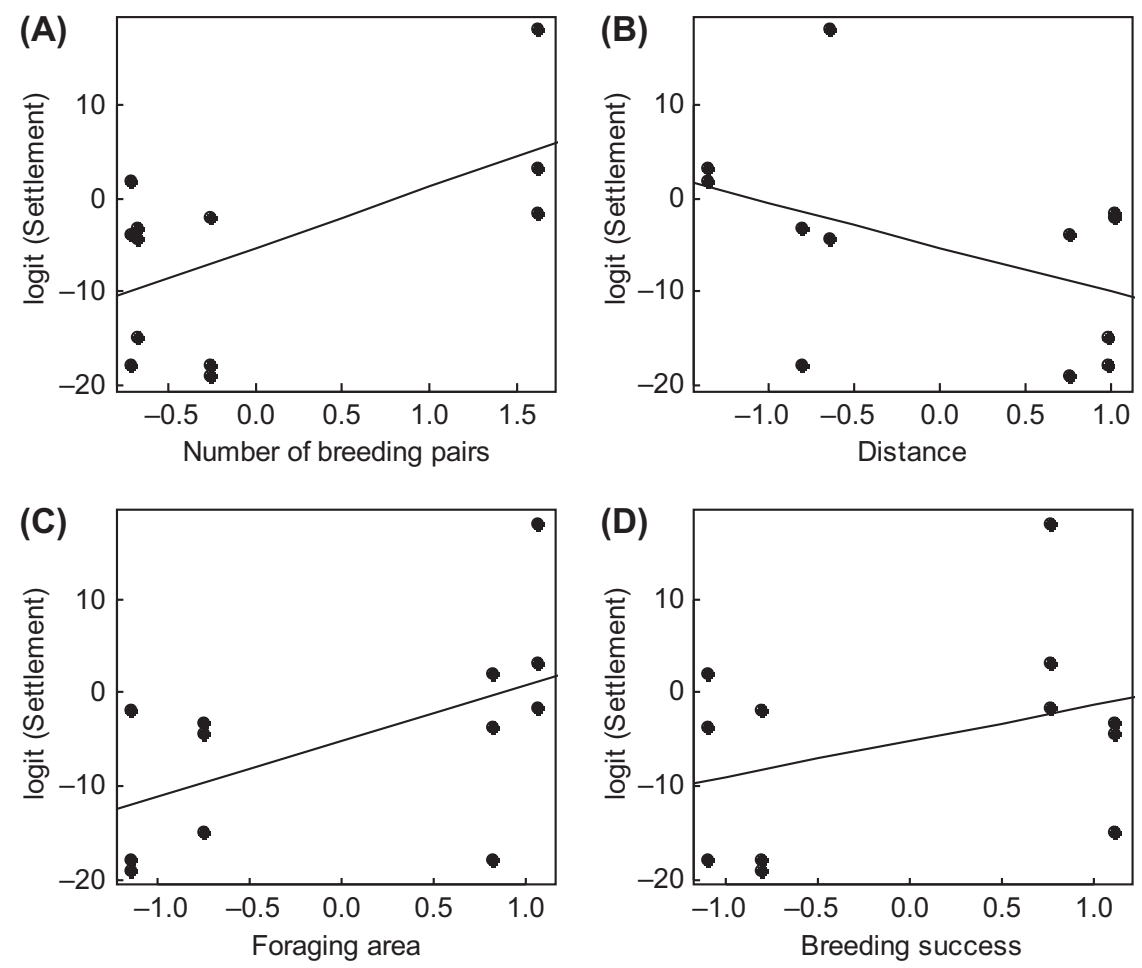

Figure 4. Relationship between settlement probabilities and the corresponding (standardized) predictor variables used in the post-hoc analyses: (A) number of breeding pairs at destination (averaged over years), (B) distance between sites, (C) foraging area at destination and (D) breeding success at destination (averaged over years). Each point represents an independent logit-transformed estimate of $\Psi$ from the most parsimonious model obtained in the multi-event modelling (model 1, Table 2).

\section{Spatial differences in survival, transience and trends in fidelity}

Because Audouin's gull is a long-lived species, it was expected that adult survival should be the less variable demographic trait (Stearns 1992). Indeed, survival was high and very similar among all local populations despite the ecological perturbations (terrestrial predation and deterioration in resource availability) occurred in the last decade at the two patches with highest population densities (Tavecchia et al. 2007, Almaraz and Oro 2011). In contrast, transience, a demographic parameter that in Audouin's gull has been identified with permanent dispersal (Oro et al. 1999, 2011, Tavecchia et al. 2007), was much higher at the two patches with lower population densities, arguably because of the both their relative low habitat quality and the higher attractiveness of larger colonies (Hanski 1999, Oro and Pradel 2000, Cam et al. 2004, Serrano et al. 2005). At Columbretes, the site with the lowest area of breeding habitat and the lowest mean breeding success and population densities, fidelity of resident breeders was much lower than in the other sites, confirming previous studies showing that habitat quality influences transience and fidelity to the patch (Serrano et al. 2001, Hoover 2003, Cam et al. 2004). At the remaining study sites, fidelity was much higher or remained high for most of the study years, probably because individuals with breeding experience in a given site are generally reluctant to disperse due to the benefits of a better knowledge of the local environment (Friesen et al. 1996, Forero et al. 1999). The association between fidelity to the breeding patch and habitat quality was confirmed also when departure probabilities increased at the two largest colonies (Ebro Delta and Chafarinas) following increasing local ecological perturbations, suggesting that the dynamics of source-sink metapopulations or any other spatially structured population depend on particular temporal stochastic environments at each patch of those systems (Doncaster et al. 1997, Oro et al. 2004). Strikingly, departure probabilities increased several years after habitat quality began to deteriorate, showing a delayed response. This suggests that only when cumulative perturbations go beyond a threshold value above which buffering is not possible for longer, site-fidelity starts to decrease (Kildaw and Irons 2005). A series of bad years in terms of breeding performance (Oro et al. 2006) may have triggered the high departure probabilities recorded from Chafarinas colony, owing to a large decrease in both individual and conspecific success (Danchin et al. 1998, Serrano et al. 2001, Kildaw and Irons 2005, Parejo et al. 2006).

\section{Settlement choices and habitat selection processes}

We found a significant positive relationship between settlement probability and population density that confirms the hypothesis of attraction towards patches with more density of conspecifics (Forbes and Kaiser 1994, Oro and Ruxton 2001, Serrano et al. 2005). Settlement probabilities appeared to decrease with distance to the recipient site, but this relationship was not statistically significant due to some distant sites being settled more frequently than others 
located at shorter distances, a finding consistent with the low dispersal costs and nomadic behaviour displayed by the species (Oro and Muntaner 2000, Martinez-Abrain et al. 2003, Parejo et al. 2006, Oro et al. 2011). Inter-colony distance also performed poorly as predictor of settlement in a multisite study on roseate terns (Spendelow et al. 1995), another seabird breeding in unstable environments. In other colonial seabirds studied using the same methodology, such as cormorants (Hénaux et al. 2007) and blackheaded gulls (Péron et al. 2010), both inter-colony distance and size of the destination colony appeared to influence settlement of breeders, but in all of them, including terns, there was a preference to settle in large colonies. Our results suggest that dispersers used the density of conspecifics as an informative cue that integrates the local availability of resources (e.g. abundance of food, suitable breeding habitat, potential mates; Doligez et al. 2004). This is why neighbouring sites such as Columbretes and Mallorca are not well connected, with disperses from these sites settling rather at the Ebro Delta. Individuals from Chafarinas, the most distant study site, remained less connected to the other patches in the system and dispersed out of the study area. This, together with the increase in dispersal from the large Ebro Delta colony, may explain the increasing colonization rates $(>90 \%$ relative to the existing and extinct patches, unpubl.) of new patches in recent years (Oro et al. 2011). In our study system, the mean breeding success of the recipient patch was not a significant driver of habitat choice and settlement for dispersing breeders and this may confirm the unreliability of breeding success as indicator of habitat quality in systems where local productivity is unpredictable (Doligez et al. 2003, Parejo et al. 2006).

In summary, our results have showed that breeding dispersal is a relatively uncommon process in our study system, with the movement of breeders increasing when cumulative perturbations (such as predation and lower availability of resources) occurred. Whereas deterioration in habitat quality decreases site fidelity and enhances dispersal, settlement decisions are primarily ruled by the density of conspecifics. Despite the low breeding dispersal probability in this species, the relative large numbers of breeders dispersing from densely populated patches may have important implications for the persistence and growth of other smaller populations both in and out of our study area.

Acknowledgements - The study has been funded by many research agencies: Spanish Ministry of Science (grants ref. BOS20000569C02-02, BOS2003-01960 and CGL2009-08298), Generalitat de Catalunya, Generalitat Valenciana, European Union (grant ref. QLRT-2000-00839), OPAN (Spanish Ministry of the Environment), the Regional Government of Balearic Islands and FEDER funding. We thank the hundreds of people helping to mark Audouin's gulls over the years and especially Gary Bortolotti (who passed away during the study). Juan Jiménez, Antoni Curcó, Javier Zapata and their technical staff kindly helped with the logistics and fieldwork campaigns. Mikko Mönkkönen kindly provided helpful comments to improve the manuscript. AF-C was supported by a FPU grant from the Spanish Ministry of Education (ref. AP2008-04476). We also thank Jill Scott for revising the English.

\section{References}

Almaraz, P. and Oro, D. 2011. Size-mediated non-trophic interactions and stochastic predation drive assembly and dynamics in a seabird community. - Ecology 92: 1948-1958.

Arcos, J. M. and Oro, D. 1996. Changes in foraging range of Audouin's gulls Larus audouinii in relation to a trawler moratorium in the western Mediterranean. - Colonial Waterbirds 19: $128-131$.

Boulinier, T. and Danchin, E. 1997. The use of conspecific reproductive success for breeding patch selection in terrestrial migratory species. - Evol. Ecol. 11: 505-517.

Boulinier, T. et al. 1997. An experimental study of the costs of reproduction in the kittiwake Rissa tridactyla: comment. - Ecology 78: 1284-1287.

Brown, J. and Kodric-Brown, A. 1977. Turnover rates in insular biogeography: effect of immigration on extinction. - Ecology 58: 445-449.

Brownie, C. et al. 1993. Capture-recapture studies for multiple strata including non-Markovian transitions. - Biometrics 49: 1173-1187.

Cadiou, B. et al. 1994. Prospecting in the kittiwake, Rissa tridactyla: different behavioural patterns and the role of squatting in recruitment. - Anim. Behav. 47: 847-856.

Cam, E. et al. 2004. Assessment of hypotheses about dispersal in a long-lived seabird using multistate capture-recapture models. - J. Anim. Ecol. 73: 723-736.

Choquet, R. and Nogue, E. 2010. E-SURGE 1.7 user's manual. - CEFE, Montpellier.

Choquet, R. et al. 2009. U-CARE: utilities for performing goodness of fit tests and manipulating CApture-REcapture data. - Ecography 32: 1071-1074.

Clobert, J. et al. 2001. Dispersal. - Oxford Univ. Press.

Danchin, E. et al. 1998. Conspecific reproductive success and breeding habitat selection: implications for the study of coloniality. - Ecology 79: 2415-2428.

Doligez, B. et al. 2003. When to use public information for breeding habitat selection? The role of environmental predictability and density dependence. - Anim. Behav. 66: 973-988.

Doligez, B. et al. 2004. Availability and use of public information and conspecific density for settlement decisions in the collared flycatcher. - J. Anim. Ecol. 73: 75-87.

Doncaster, C. et al. 1997. Balanced dispersal between spatially varying local populations: an alternative to the sourcesink model. - Am. Nat. 150: 425-445.

Forbes, L. S. and Kaiser, G. W. 1994. Habitat choice in breeding seabirds: when to cross the information barrier. - Oikos 70: 377.

Forero, M. et al. 1999. Causes and consequences of territory change and breeding dispersal distance in the black kite. - Ecology 80: 1298-1310.

Friesen, V. et al. 1996. Molecular evidence for kin groups in the absence of large-scale genetic differentiation in a migratory bird. - Evolution 50: 924-930.

González-Solís, J. 2003. Impact of fisheries on activity, diet and predatory interactions between yellow-legged and Audouin's gulls breeding at the Chafarinas Islands. - Sci. Mar. 67: 83-88.

Gotelli, N. 1991. Metapopulation models: the rescue effect, the propagule rain, and the core-satellite hypothesis. - Am. Nat. 138: 768-776.

Greenwood, P. and Harvey, P. 1982. The natal and breeding dispersal of birds. - Annu. Rev. Ecol. Syst. 13: 1-21.

Grosbois, V. and Tavecchia, G. 2003. Modeling dispersal with capture-recapture data: disentangling decisions of leaving and settlement. - Ecology 84: 1225-1236.

Hanski, I. 1999. Metapopulation ecology. - Oxford Univ. Press. 
Hénaux, V. et al. 2007. Dispersal and recruitment during population growth in a colonial bird, the great cormorant Phalacrocorax carbo sinensis. - J. Avian Biol. 38: 44-57.

Hoover, J. 2003. Decision rules for site fidelity in a migratory bird, the prothonotary warbler. - Ecology 84: 416-430.

Jenouvrier, S. et al. 2008. Recruitment processes in long-lived species with delayed maturity: estimating key demographic parameters. - Oikos 117: 620-628.

Kildaw, S. and Irons, D. 2005. Formation and growth of new seabird colonies: the significance of habitat quality. - Mar. Ornithol. 33: 49-58.

Lebreton, A. J. et al. 1992. Modeling survival and testing biological hypotheses using marked animals: a unified approach with case studies. - Ecol. Monogr. 62: 67-118.

Liu, Y. and Zhang, Z. 2008. Research progress in avian dispersal behavior. - Front. Biol. China 3: 375-384.

Martinez-Abrain, A. et al. 2003. Modeling temporal and spatial colony-site dynamics in a long-lived seabird. - Popul. Ecol. 45: 133-139.

Mönkkönen, M. et al. 1997. Heterospecific attraction affects community structure and migrant abundances in northern breeding bird communities. - Can. J. Zool. 75: 2077-2083.

Nathan, R. 2001. The challenges of studying dispersal. - Trends Ecol. Evol. 16: 481-483.

Oro, D. and Pradel, R. 1999. Recruitment of Audouin's gull to the Ebro Delta colony at metapopulation level in the western Mediterranean. - Mar. Ecol. Prog. Ser. 180: 267-273.

Oro, D. and Muntaner, J. 2000. La gaviota de Audouin en Cabrera. - In: Pons, G. (ed.), Las aves del Parque Nacional marítimoterrestre del Archipiélago de Cabrera (Islas Baleares, España). GOB-Colecciones Técnicas del Ministerio de Medio Ambiente, pp. 95-112.

Oro, D. and Pradel, R. 2000. Determinants of local recruitment in a growing colony of Audouin's gull. - J. Anim. Ecol. 69: 119-132.

Oro, D. and Ruxton, G. D. 2001. The formation and growth of seabird colonies: Audouin's gull as a case study. - J. Anim. Ecol. 70: 527-535.

Oro, D. et al. 1999. Food availability and nest predation influence life history traits in Audouin's gull, Larus audouinii. - Oecologia 118: 438-445.

Oro, D. et al. 2004. Influence of food availability on demography and local population dynamics in a long-lived seabird. - Proc. R. Soc. B 271: 387-396.

Oro, D. et al. 2006. Influence of density dependence on predatorprey seabird interactions at large spatio-temporal scales. - Proc. R. Soc. B 273: 379-383.

Oro, D. et al. 2011. Comparing demographic parameters for philopatric and immigrant individuals in a long-lived bird adapted to unstable habitats. - Oecologia 165: 935-945.

Paradis, E. et al. 1998. Patterns of natal and breeding dispersal in birds. - J. Anim. Ecol. 67: 518-536.
Parejo, D. et al. 2006. Testing habitat copying in breeding habitat selection. - Ibis 148: 146-154.

Pedrocchi, V. et al. 2002. Differences in diet between the two largest breeding colonies of Audouin's gulls: the effects of fishery activities. - Sci. Mar. 66: 313-320.

Péron, G. et al. 2010. Breeding dispersal in black-headed gull: the value of familiarity in a contrasted environment. - J. Anim. Ecol. 79: 317-326.

Pradel, R. 2005. Multievent: an extension of multistate capture-recapture models to uncertain states. - Biometrics 61: 442-447.

Pradel, R. and Sanz-Aguilar, A. 2012. Modeling trap-awareness and related phenomena in capture-recapture studies. - PloS one 7: e32666.

Pradel, R. et al. 1997. Capture-recapture survival models taking account of transients. - Biometrics 53: 60-72.

Pradel, R. et al. 2003. A proposal for a goodness-of-fit test to the Arnason-Schwarz multisite capture-recapture model. - Biometrics 59: 43-53.

Ruiz, X. et al. 1998. Body size variation in Audouin's gull Larus audouinit: a density-dependent effect? - Ibis: 431-438.

Sanz-Aguilar, A. et al. 2011. Studying the reproductive skipping behavior in long-lived birds by adding nest inspection to individual-based data. - Ecol. Appl. 21: 555-564.

Schaub, M. and Von Hirschheydt, J. 2009. Effect of current reproduction on apparent survival, breeding dispersal, and future reproduction in barn swallows assessed by multistate capture-recapture models. - J. Anim. Ecol. 78: 625-635.

Schjørring, S. et al. 1999. Prospecting enhances breeding success of first-time breeders in the great cormorant, Phalacrocorax carbo sinensis. - Anim. Behav. 57: 647-654.

Serrano, D. et al. 2001. Factors affecting breeding dispersal in the facultatively colonial lesser kestrel: individual experience vs. conspecific cues. - J. Anim. Ecol. 70: 568-578.

Serrano, D. et al. 2005. Colony size selection determines adult survival and dispersal preferences: allee effects in a colonial bird. - Am. Nat. 166: E22-E31.

Smith, A. T. and Peacock, M. M. 1990. Conspecific attraction and the determination of metapopulation colonization rates. - Conserv. Biol. 4: 320-323.

Spendelow, J. A. et al. 1995. Estimating annual survival and movement rates of adults within a metapopulation of roseate terns. - Ecology 76: 2415-2428.

Stearns, S. 1992. The evolution of life histories. - Oxford Univ. Press.

Tavecchia, G. et al. 2001. Sex-and age-related variation in survival and cost of first reproduction in greater flamingos. - Ecology 82: $165-174$.

Tavecchia, G. et al. 2007. Density-dependent parameters and demographic equilibrium in open populations. - Oikos 116: 1481-1492. 